MIDPI

MOL2NET, International Conference Series on Multidisciplinary Sciences

http://sciforum.net/conference/mol2net-03

sciforum

\title{
Application of Molecular Topology to the Analysis of Antimalarial Activity of 4-Aminobicyclo[2.2.2]Octan-2-yl 4-Aminobutanoate and their Equivalents Ethanoates and Propanoates
}

I. Baptista-Peraza ${ }^{a}$ (ivirbap@alumni.uv.es), C. Otero-Pérez ${ }^{a}$ (opeca@alumni.uv.es), S. GonzálezApráez ${ }^{a}$ (segona@alumni.uv.es), A. Pertegás-Sevillaa (aperse@alumni.uv.es), J. Gálvez ${ }^{\text {b }}$ (jorge.galvez@uv.es) and R. García-Domenech ${ }^{\mathrm{b}}$ (ramon.garcia@uv.es)

${ }^{a}$ Departamento de Farmacia y Tecnología Farmacéutica y Parasitología, Facultad de Farmacia, Universitat de València, Spain

${ }^{b}$ Departamento de Química Física, Facultad de Farmacia, Universitat de València Spain

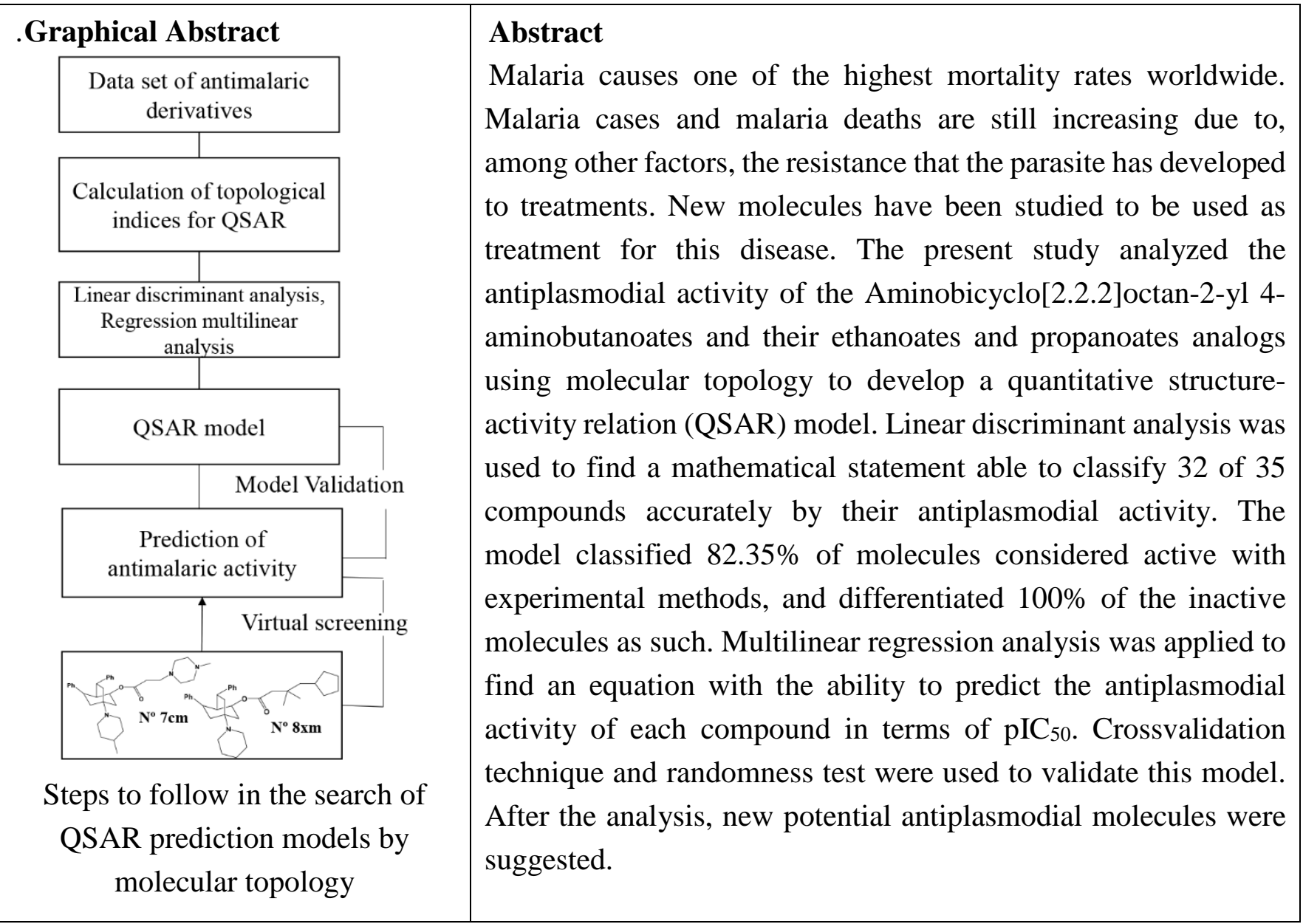

\section{References}

Weis R, Seebacher W, Brun R, Kaiser M, Sat R, Faist J.. Monatsh Chem 2013: https://doi.org/10.1007/s00706-013-1116-2 Mahmoudi N, García-Domenech R, Gálvez J, et al. New active drugs against liver stages of Plasmodium predicted by molecular topology. Antimicrob Agents Chemother 2008 Apr;52(4):1215-1220.

Nereis 11, pp. 51-64: https://www.ucv.es/investigacion/publicaciones/catalogo-de-revistas/revista-nereis 